\title{
The Effects of DRRR Policy on Large versus S\&M Sized Banks in China
}

\author{
Guo Xiaohui ${ }^{1 *}$ and Kang Shusheng ${ }^{2}$ \\ ${ }^{1}$ School of Economics, Hebei University, Baoding, 071002, China \\ ${ }^{2}$ School of Economics, Hebei University, Baoding, 071002, China
}

\begin{abstract}
This paper employs cointegration test to measure the effects of Differentiated Reserve Requirement Ratio (DRRR) policy on large banks versus Small and Medium (S\&M) sized banks from 2009M01 to 2013M10. The results confirm the hypothesis that this DRRR policy promotes the economy growth more in the earthquake-stricken counties and a lower DRRR to some extent alleviate the tightening effects of RRR on the S\&M sized banks. Due to the big regional disparity, the PBC can consider expand the use of this DRRR policy to more less developed regions to make a more coordinated regional economic development in China.
\end{abstract}

\section{Introduction}

In recent years, along with the deepening of economic reform and opening up, to cope with the complicated domestic and international economic situation, the PBC (the People's Bank of China, central bank of China) has begun to make some new tries to the implementation of monetary policy instruments. The PBC has introduced Differentiated Reserve Requirement Ratio (DRRR) policy since April 25th, 2004. The main content of DRRR policy is that the required reserve ratio applicable to a financial institution will be linked with such indicators as its capital adequacy ratio and asset quality. The lower the capital adequacy ratio of a financial institution and the higher its NPL (Non-Performing Loan) ratio, a higher required reserve ratio will be charged. The purpose of this policy is to limit the loan expansion of those financial institutions with inadequate capital and poor asset quality, reduce financial risk and maintain financial stability.

DRRR policy said that financial institutions whose capital adequacy ratios were below $4 \%$ would apply the DRRR $0.5 \%$ higher than normal level. Since this policy applied, 38 joint-stock banks and city commercial banks such as Guangdong Development Bank, China Everbright Bank and Shenzhen Development Bank have been applied DRRR 0.5\% higher than normal level as their loan growth is too fast and the risk is too high. In July, 2006, the Agricultural Bank of China also was forced to apply DRRR 0.5\% higher than normal level.

In practice, the PBC also attempted to implement DRRR based on regions and the structure of credit to continuously extend the application of DRRR policy. Since September $21 \mathrm{st}, 2003$, all financial institutions that took deposits from the public have had to meet a

* Corresponding author: nlmh6@126.com 
uniform reserve requirement ratio of seven percent, with the exception of the Urban and Rural Credit Cooperatives that still abide by the six percent standard. To support the development of rural area, the PBC did not raise the reserve requirement ratio of Rural Credit Cooperative until 2006. On May 12th, 2008, a big earthquake hit Sichuan province and made lots of damage. To support the reconstruction of the disaster area, the PBC has applied DRRR a little lower than normal level to the disaster area in Sichuan province that suffered most in the earthquake from June 8th, 2008 to June, 2011.

Global financial crisis happened in 2008 made the domestic and overseas economic condition become much more complicated. Facing this situation, the PBC decided to apply DRRR to different sizes of financial institutions. On September 25th, 2008, the PBC applied DRRR to Large banks and Small \& Medium sized banks (S\&M sized banks). Large banks applied the DRRR 1\% higher than S\&M sized banks. Large banks occupied a bigger market shares, applying a higher DRRR was helpful for the PBC to control money and credit supply. Considering most of loans made by S\&M sized banks flowed to S\&M sized enterprises (China Banking Regulatory Commission Annual Report 2011 ), the PBC applied a little lower DRRR to S\&M sized banks so as to solve the difficulty of financing in S\&M sized enterprises. Now large and S\&M sized banks apply Different Deposit Reserve Ratio separately (see Figure 1).

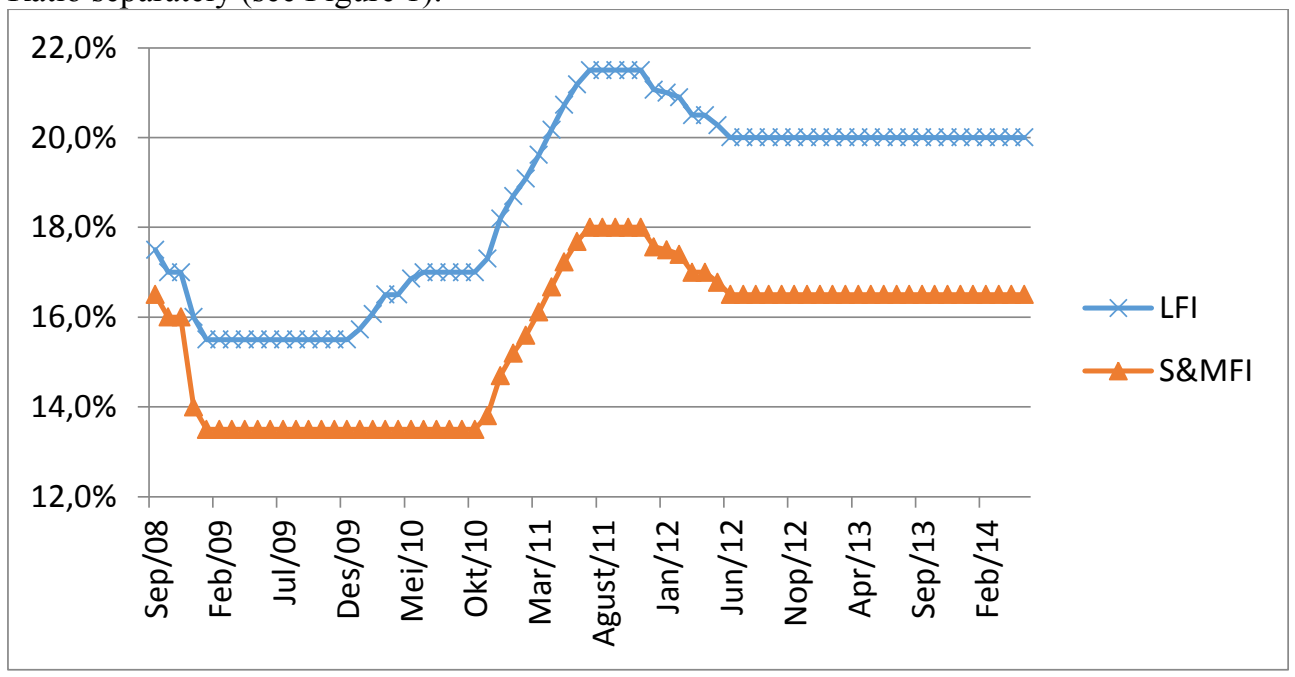

Fig.1. Differentiated Reserve Requirement Ratio in China from 2008M08 to 2014M05, Sources: The People's Bank of China, Notes: LFI: deposit reserve ratio of Large Financial institutions. S\&MFI: deposit reserve ratio of Small and Medium sized Financial Institutions.

The initial purpose of DRRR policy is to limit the loan expansion of those financial institutions with inadequate capital and poor asset quality. In its subsequent development, the PBC tries to use this monetary policy instrument to promote the economy growth of certain region (such as the earthquake-stricken area) and adjust the credit structure (DRRR policy to Large and S\&M sized bank). If the practice can prove that this policy plays an important role in these areas as expected, then the implementation of DRRR policy has a significant meaning to the PBC: first, the shortcoming of traditional monetary policy is that "one size fit all" practice doesn't consider the unbalance of regional economies. But to some extent this DRRR policy can solve this problem. Second, the PBC can use this policy to adjust the structure of credit. For example, they can apply a higher DRRR to large banks to curb inflation 
while at the same time implementing a lower DRRR to S\&M sized banks to solve the difficulty of financing in S\&M sized enterprises.

Therefore, in this study, we will use the earthquake-stricken area and large and S\&M sized bank to do case studies in order to examine the effects of DRRR policy. The organization of this study is as follows: the next section discusses briefly literature review. Section three devotes on methodology and section four highlights the empirical results. Section five is conclusion and limitations.

\section{Literature Review}

The traditional description of monetary policy generally emphasizes the reserve requirement constraint on banks. In this story, banks are an important link in the transmission of monetary policy because changes in bank reserves influence the quantity of reservable deposits held by banks (Peek and Rosengren, 1995). Raising the reserve requirement constraint can limit monetary growth and squeeze excess reserves if not fully neutralized, potentially limiting banks' capacity to lend over time (Ma, Yan and Liu, 2011).

It is generally accepted that reserve requirements act as a tax on banks and thus hurt their profits, affecting cost of credit and possibly inducing them to widen the loan-deposit rate spread (Borio and Disyatat, 2009; Montoro and Moreno, 2011). Banks are motivated to transfer the cost imposed by reserve requirements via attempts to either pay depositors less or charge borrowers more or both - by widening the loan-deposit rate spread (Montoro and Moreno, 2011). This rests on the implicit assumption that the burden can be passed through.

Hein and Jonathan (2002) point out that while it is generally accepted that reserve requirements act as a tax on banks, there is widespread disagreement that as to who bears the tax and who benefits when the tax is reduced. Black (1975) and Fabozzi and Thurston (1986) argue that the reserve requirement tax is passed on to depositors of reservable instruments in the form of lower yields. Cargill and Mayer (2005) find that banks do not respond to the changes in reserve requirements essentially by changing their excess reserves, instead, banks meet a substantial part of their increased reserve requirements by reducing their earning assets, including loans. They prove that the increase in reserve requirements reduces the availability of bank credit.

There is much recent evidence suggesting that at least a portion of the tax is not passed on to borrowers or depositors but rather is passed on to, or absorbed by, bank shareholders. Some authors (Osborne and Zaher, 1992; Cosimano and McDonald, 1998; and Stewart and Hein, 2002) provide evidences suggesting that increases (reductions) in reserve requirements lead to lower (higher) bank stock prices.

According to the bank lending channel thesis, monetary policy actions can also alter the supply of bank loans by changing bank reserves, and thus on the real economy (Kashyap and Stein, 1994). By lowering bank reserves, contractionary policy can decrease the core deposit funding of bank loans (due to reserve requirements) (Van Den Heuvel, 2002). If some banks (such as small banks) are unable to raise nonreservable funds to continue lending, policy will decrease their loan supply and affect their bank-dependent borrowers. Decreases in either loan supply or loan demand lead to reduced investment and consumption expenditures (Kishan and Opiela, 2000).

Ma, Yang and Liu (2011) argue that the PBC finds it easier to reach consensus on reserve requirements than interest rate decisions and enjoys greater discretion in applying this tool in recent years. The effects of reserve requirements should be explored in conjunction with other policy actions. Depending on the policy mix, higher reserve requirements tend to signal a tightening bias, to squeeze excess reserves of banks, to push 
market interest rates higher, and to help widen net interest spreads, thus tightening domestic monetary conditions. It is well known that reserve requirements is seemed as a tax burden on banks. Banks appear to pass through a big part of the burden to their customers, mostly depositors and small and medium-sized enterprises (SMEs). Yet bank shareholders may also bear part of the burden, if wider margins and spreads in part reflect increased risk premia.

In all, most of the literature analyzes the function of reserve requirements and the link between reserve requirements ratio and bank loans. Only Gray (2011) gives a simple description of differentiated reserve requirement ratio. Gray (2011) indicates that most of countries use a single reserve requirement rate for all reservable liabilities, a few countries use differentiated reserve requirements ratio with clear and achievable goals. Historically, some central banks have applied differential reserve requirements ratio to different types of banks (such as the United States set reserve requirements ratio based on geographic distinctions among member banks and the level of deposits during 1966-1972). This would appear to reflect the taxation aspect of unremunerated reserves, and implies a subsidy to those banks which have a lower reserve requirement.

To our knowledge, no literature tests the effects of DRRR policy on different regions and large VS S\&M sized banks. We will do these tests to examine the effects of DRRR policy on the disaster region and the loans made by large VS S\&M sized banks in China.

\section{Methodology}

As we have two objectives, the first one is to check the effects of DRRR policy on the GDP growth of earthquake-stricken area, the second one is to examine the impacts of DRRR policy on the loans made by large VS S\&M sized banks in China, we also have two models. The first one is panel data model and the second one is cointegration test.

\subsection{The First Model}

In the first model, we want to check the role of DRRR policy on the outputs of the quake-stricken areas. As the 2008 Wenchuan earthquake mainly happenes in Sichuan province, we select 39 counties which are badly hurt by the earthquake and enjoy the preferential DRRR policy in Sichuan province and the other 39 counties in Sichuan province which do not apply the DRRR policy to make a comparison to check whether or not the DRRR policy can promote the GDP growth more in the quake-stricken 39 counties than normal RRR (Reserve Requirement Ratio) policy implemented in the other 39 counties. The estimation period is the implementation period of the DRRR policy during 2008-2011.

We construct our first model mainly based on the expenditure approach of GDP. As well known, GDP mainly contains four parts: government expenditure, investment, consumption and net exports. As these 78 counties in Sichuan province belong to the less developed western region, far from the coastal areas, there are very little or no exports in these counties, we neglect net exports in our model. We divide investment into two parts: in the first part, the funds of investment are from bank loans, in the second part, the funds are from other sources. According to the bank lending channel, we know that reserve requirement ratio can affect loans and the change of loans can influence investment, and finally will affect the real economy. We assume that the DRRR can affect the investment through loans, thus we introduce an interaction item: DRRR*Loans, into GDP equation. We assume that the interaction item mainly affects the first part of investment and want to measure the influence of this interaction item on the GDP. Therefore, we get our model like this: 


$$
G D P_{i t}=\alpha_{i}+\text { Govexp }_{i t} \beta_{i}+\text { DDRR }_{i t} * \operatorname{Loan}_{i t} \gamma_{i}+\text { Othinvest }_{i t} \delta_{i}+\text { Consum }_{i t} \sigma_{i}+e_{i t}
$$

Where GDPit is the GDP of 39 counties in Sichuan province, $t=2008,2009,2010$ and 2011. $\mathrm{i}=1,2, \ldots \ldots, 39$. The loanit is the total loan of each county. Govexp $p_{i t}$ is government expenditure measured by the local government intra-budgetary ordinary expenditure of each county. Oth invest $t_{i t}$ is the investment whose funds are from other sources (except bank loans) measured by total investment in fixed assets (minus bank loans) of each county. Consumit is consumption measured by total retail sales of consumer goods in each county. These variables are real variables adjusted by the CPI index $(2008=100)$. DRRRit is Differentiated Reserve Requirement Ratio. As the counties in Sichuan province are less developed areas located in inland China, they do not have or have very little FDI, thus we do not add FDI as an independent variable. eit are residuals.

We will use panel data model to estimate this equation. The data cover 78 counties in Sichuan province from 2008 to 2011. Firstly we will estimate the model for the 39 earthquake badly hurt counties which enjoy the DRRR policy in Sichuan province, and then we estimate the model for the other 39 counties without the DRRR policy in Sichuan province. We will compare the coefficients: $\gamma_{i}$ to check the effects of DRRR policy on the GDP growth of the counties with DRRR policy and counties without DRRR policy. In this model, we do not use dummy variable to differentiate the earthquake-stricken counties and the other counties, because what we want to know is whether or not the preferential DRRR can support the economy growth of the disaster counties, not whether the earthquake can influence the economic growth in these counties or not.

\subsection{The Second Model}

In the second model, we will examine the role of DRRR policy on the loan made by large and S\&M sized banks. We adopt the model developed by Zhang, Ji and Cui (2008), but we make a little modification. The loan supply is mainly influenced by the reserve requirement ratio and the spread between the benchmark loan rate and deposit rate which regulated by the PBC. The loan demand is mainly affected by the economic condition (measured by the GDP). Thus we set our third model as follows:

$$
\text { Loans }_{t}=\alpha+D D R R_{t} \beta+\text { Spread }_{t} \gamma+G D P_{t} \theta+e t
$$

Where loans is the total loan made by Large banks and S\&M sized banks. DRRR ${ }_{i t}$ is Differentiated Reserve Requirement Ratio. Spread is the spread between the benchmark loan rate and deposit rate which regulated by the PBC. As we cannot get the monthly data of GDP, we use real industrial value added as a proxy. e are residuals. We test the model using monthly data from 2009M01 until 2013M10.

Cointegration test is an econometrics method that is applied to investigate the existence of any long-run equilibrium between variables. If a group of time series is cointegrated, the variables are assumed to have a long run equilibrium relationship. Long run equilibrium relationship can be defined as a group of time series that tend to move together through time in a long period of time and the difference between them are stable although in the short run they may diverge from each other. As the estimation period is from 2009M01 to 2013M06 using monthly data, we will use VEC (Vector Error Correction) model to run the cointegration test separately for large banks and the S\&M sized banks. We will compare the coefficients $\beta$ to compare the role of DRRR policy on the large banks versus S\&M banks. 


\section{Empirical Results}

\subsection{Results of the First Model}

In panel data analysis, we estimate three models: pooled regression model, fixed effects model and random effects model. We use Pooled Ordinary Least Squares (POLS) to estimate the pooled regression model, use Least Squares Dummy Variable (LSDV) to estimate the fixed effects and Generalized Least Squares (GLS) to estimate random effects model. The results are in table 1.

In table 1, we estimate model 1 for the 39 earthquake badly hurt counties with DRRR policy, model 2 for the other 39 counties without the DRRR policy in Sichuan province. At the first glance, we can see the coefficient of the interaction part DRRR*Loans of model one is bigger than that of model two in all regressions.

Then we run the Likelihood ratio test and Hausman test to see which model is the best one. For model one, first we run the Likelihood ratio test, the cross-section F-statistic is 37.8345 , the P-value is 0.0000 , so we reject the null hypothesis that the proper model is pooled regression model. Then we run the Hausman test to compare the fixed effects and random effects, if the Hausman test rejects the null hypothesis, the fixed effects model is appropriate, or the random effects model is estimated (Hausman, 1978). The Chi-Sq. Statistic is 9.8087 and $\mathrm{P}$-value is 0.0438 , thus we reject the null hypothesis, the final model is fixed effects model. In model two, for Likelihood ratio test, the cross-section F-statistic is 50.9824, the P-value is 0.0000 , for the Hausman test, the Chi-Sq. Statistic is 9.2490 and Pvalue is 0.0552 , the null hypothesis cannot be rejected and we choose the random effects model as the best model.

Table 1. Results of the First Model

\begin{tabular}{|l|l|l|l|l|l|l|}
\hline \multicolumn{7}{|l|}{ Dependent Variable (DV): The GDP of Each County } \\
\hline & \multicolumn{7}{|l|}{ Fooled Regression } & \multicolumn{2}{l|}{ LSDV } & \multicolumn{1}{l|}{ GLS } \\
\hline Method & POLS & \multicolumn{7}{l|}{ Mandom Effects } \\
\hline IV & Model 1 & Model 2 & Model 1 & Model 2 & Model 1 & Model 2 \\
\hline Intercept & 8313.620 & $-19642.29(-$ & $127673.5^{* * *}$ & $141629.2^{* * *}$ & $97443.01^{* *}$ & $110396.3^{* *}$ \\
& $(0.2483)$ & $0.4720)$ & $(4.6397)$ & $(4.5538)$ & $(2.5172)$ & $(2.5199)$ \\
\hline Govexp & 0.1075 & $1.6609^{* * *}$ & 0.0187 & $1.1864^{* * *}$ & 0.0704 & $1.1052^{* * *}$ \\
& $(0.7446)$ & $(4.0155)$ & $(0.2645)$ & $(5.5581)$ & $(1.0599)$ & $(5.4733)$ \\
\hline DRRR*Loans & $2.4510^{* * *}$ & $2.1256^{* * *}$ & $2.1382^{* * *}$ & $1.8848^{* * *}$ & $2.2096^{* * *}$ & $1.6614^{* * *}$ \\
& $(8.1831)$ & $(3.3684)$ & $(9.2374)$ & $(4.8838)$ & $(10.4767)$ & $(4.6499)$ \\
\hline Othinvest & $0.1086^{* *}$ & 0.1422 & 0.0096 & $0.2344^{* * *}$ & 0.0081 & $0.2128^{* * *}$ \\
& $(1.9971)$ & $(1.5602)$ & $(0.4023)$ & $(4.7386)$ & $(0.3522)$ & $(4.5181)$ \\
\hline Consum & $1.7354^{* * *}$ & $1.4405^{* * *}$ & $1.6998^{* * *}$ & $1.0650^{* * *}$ & $1.7545^{* * *}$ & $1.2763^{* * *}$ \\
& $(16.0563)$ & $(6.3429)$ & $(13.3535)$ & $(5.0503)$ & $(16.4983)$ & $(6.9874)$ \\
\hline Adjusted R & 0.9315 & 0.8763 & 0.9933 & 0.9909 & 0.9305 & 0.9342 \\
\hline Observations & 156 & 156 & 156 & 156 & 156 & 156 \\
\hline
\end{tabular}

Notes: T-statistics in parentheses. *, **, and $* * *$ indicates that a null hypothesis of zero is rejected at the $10 \%, 5 \%$, and $1 \%$ levels, respectively

In the fixed effects model, we can see in model one (the earthquake-stricken counties), the coefficients of government expenditure and other investments are positive and nonsignificant. The coefficients of the interaction part, consumption and the intercept are positive and statistically significant. In the random effect model, all the coefficients of model two are positive and significant. The coefficient of the interaction part is the combined effect of the DRRR and loans on the GDP. This coefficient in model one (fixed effects model) is bigger than that in model 2 (random effects model). Ceteris paribus, considering all these 78 counties are in the same province Sichuan, located in the adjacent 
places, almost share the same economic development level, thus we can say that it is the DRRR policy which mainly causes the difference. In earthquake-stricken counties, the combined effect of lower DRRR and more loans is about $28.70 \%$ bigger than that in the other 39 counties, indicating that the preferential DRRR in the earthquake-stricken counties is effective and do can help the economy of the less developed disaster counties to gain more growth than the normal RRR in other counties.

\subsection{Results of the Second Model}

In the second model, we use the cointegration test to examine the role of DRRR policy on the loan made by large and S\&M sized banks using monthly data from 2009M01 to 2013M10. The variables used in the estimation must be stationary so that standard statistical theory applies. We conduct augmented Dickey-Fuller (ADF) unit root tests applied to the levels and first-difference of the system's variables in EViews 6.0 (see Table 2 ). The data of Loans and GDP are seasonally adjusted and expressed in logs. From table 2 we can see that all the variables are I(1), then we run the cointegration test separately for large banks and S\&M sized banks. The lag length is 8 for large banks and 4 for S\&M sized banks. We can see the results from table 3 and 4.

Table 2. Unit root tests for the variables

\begin{tabular}{|l|l|l|l|l|}
\hline \multirow{2}{*}{ Variables } & \multicolumn{2}{|c|}{ Level } & \multicolumn{2}{c|}{ First Difference } \\
\cline { 2 - 5 } & \multicolumn{1}{|c|}{ Constant } & \multicolumn{1}{c|}{$\begin{array}{c}\text { Constant with } \\
\text { trend }\end{array}$} & \multicolumn{1}{c|}{ Constant } & $\begin{array}{c}\text { Constant with } \\
\text { trend }\end{array}$ \\
\hline Lnbloan_sa & $-4.8537^{* * *}$ & $-7.0690^{* * *}$ & -1.7897 & $-5.9714^{* * * *}$ \\
Lnsloan_sa & -2.3818 & -2.3671 & $-7.5485^{* * *}$ & $-7.9350^{* * *}$ \\
LnGDP_sa & $-2.9773^{* *}$ & $-5.7259^{* * *}$ & $-7.3610^{* * *}$ & $-6.4489^{* * *}$ \\
LDRRR & -1.5162 & -1.3165 & $-3.1017^{* *}$ & $-3.2273^{*}$ \\
SDRRR & -1.5511 & -3.0239 & $-2.8136^{*}$ & -2.8393 \\
Spread & -0.3260 & -1.6557 & $-6.1777^{* * *}$ & $-6.2002^{* * *}$ \\
\hline
\end{tabular}

Notes: Asterisk $*, * *$ and $* * *$ indicates the rejection of the null hypothesis at level of confidence $10 \%, 5 \%$ and $1 \%$ respectively, critical values are from Davidson and Mackinnon (1993). The null and alternative hypothesis are respectively $\mathrm{H} 0=$ unit root (series is non-stationary) and $\mathrm{H} 1>0$ (series is non-stationary). Based on the Akaike Information Criterion (AIC) and Schwarz Information Criterion (SC), considering the degree of freedom, the lag lenth is two.

Table 3. Cointegration Rank Test (Trace) for Large Banks

\begin{tabular}{|c|c|c|c|c|}
\hline $\begin{array}{l}\text { Hypothesized No. of } \\
\text { CE(s) }\end{array}$ & Eigenvalue & Trace Statistic & $\begin{array}{l}\text { 0.05 } \\
\text { Critical Value }\end{array}$ & Prob. ${ }^{* *}$ \\
\hline None * & 0.54114 & 65.76838 & 47.85613 & 0.0005 \\
\hline At most 1 & 0.342734 & 28.37586 & 29.79707 & 0.0722 \\
\hline At most 2 & 0.114773 & 8.231883 & 15.49471 & 0.4409 \\
\hline At most 3 & 0.048377 & 2.380138 & 3.841466 & 0.1229 \\
\hline
\end{tabular}

Notes: Trace test indicates 1 cointegrating equation at the 0.05 level. * denotes rejection of the hypothesis at the 0.05 level. ** denotes MacKinnon, Haug and Michelis (1999) p-values.

Table 4. Cointegration Rank Test (Trace) for S\&M Sized Banks

\begin{tabular}{|c|r|r|r|r|}
\hline $\begin{array}{c}\text { Hypothesized } \\
\text { No. of CE(s) }\end{array}$ & \multicolumn{1}{|c|}{ Eigenvalue } & \multicolumn{1}{c|}{ Trace Statistic } & $\begin{array}{c}\mathbf{0 . 0 5} \\
\text { Critical Value }\end{array}$ & Prob. $^{* *}$ \\
\hline None $^{*}$ & 0.395723 & 55.71469 & 47.85613 & 0.0077 \\
\hline
\end{tabular}




\begin{tabular}{|c|c|c|c|c|}
\hline At most 1 & 0.243278 & 29.52113 & 29.79707 & 0.0538 \\
\hline At most 2 & 0.179143 & 15.02565 & 15.49471 & 0.0587 \\
\hline At most $3^{*}$ & 0.087483 & 4.760528 & 3.841466 & 0.0291 \\
\hline
\end{tabular}

Notes: Trace test indicates 1 cointegrating equation at the 0.05 level. ${ }^{*}$ denotes rejection of the hypothesis at the 0.05 level. ** denotes MacKinnon, Haug and Michelis (1999) p-values.

According to table 3 and 4, cointegration tests show that one cointegrating equation exists for large banks and S\&M sized banks, indicating the existence of long run equilibrium relationship between these variables. We write the cointegrating equations as follows:

For large banks:

$$
\text { Dlnbloan }_{s a}=-1.0767 D L D D R R+32.6405 \text { DSpread }+1.4284 D L n G D P
$$

For S\&M sized banks:

$$
\text { Dlnsloan }_{\text {sa }}=-3.4271 D S D D R R+83.5923 \text { DSpread }+1.4284 D L n G D P
$$

The log likelihood of equation (3) and (4) are 1105.053 and 964.6038. For equation (3), the coefficient of LDRRR is -1.0767 , which means when the DRRR for large banks raises one percent, the loans of large banks in logs will reduce 1.0767 million CHY. That is to say, the loans of large banks will reduce 2.9350 million CHY. The loan of large banks is positively related to the spread and the GDP, indicating that when the spread increases and the economy grow fast, the loans will increase. The equation (4) is for S\&M sized banks. The coefficient of LDRRR is -3.4271 , which means when the DRRR for S\&M sized banks raises one percent, the loans of S\&M sized banks in logs will reduce 3.4271 million CHY and the loans of large banks will reduce 30.7872 million CHY. Compared with equation (3) and (4), we can see that the S\&M sized banks are more easily affected by the reserve requirement ratio, the spread and the real conditions of the economy. When the PBC raises the RRR one percent, this action apparently influence the S\&M sized banks more. Therefore, it is proper that the PBC applies the DRRR policy to the banking system, the large banks apply a little higher RRR and the S\&M sized banks apply a little lower RRR. However, comparing equation (3) and (4), we can see that although the S\&M sized banks apply the lower DRRR, the tightening effects on them (coefficient of SDRRR) is still much bigger than that on large banks. Therefore, there are still some room to reduce the DRRR for the S\&M sized banks.

\section{Conclusion}

This study uses panel data analysis to examine the effects of DRRR policy on the earthquake-stricken area during 2008-2011 and employs the cointegration test to measure the effects on large banks versus S\&M sized banks from 2009M01 to 2013M10. The results confirm our hypothesis that this DRRR policy promotes the economy growth more in the earthquake-stricken counties and a lower DRRR to some extent alleviate the tightening effects of RRR on the S\&M sized banks.

Our results have a profound policy implication. As China is a huge country and the regional disparity is obvious (Lau, 2010; Fan, Kanbur and Zhang, 2011; Pedroni and Yao, 2006), common monetary policy may have regional effects on different provinces and these 
regional effects may increase the gap among regions in China. This study provides an empirical proof that we can narrow the gap from the perspective of monetary policy.

When the PBC formulates and implements the common monetary policy, they should take the different effects of monetary policy into account. This Differentiated Deposit Requirement Ratio (DRRR) policy is a new try by the PBC. Our finding proves that this DRRR policy does support the economy growth of the disaster area and a lower DRRR to some extent can alleviate the tightening effects of RRR on the S\&M sized banks. Then we can suggest that the PBC can consider expanding to apply this DRRR policy to more less developed provinces (Such as some provinces in the Middle and West) or some rural areas in order to promote a more coordinated regional economic development. For different banks, our results show that the PBC apply a lower DRRR to S\&M sized banks is reasonable but not enough. Although the S\&M sized banks apply a lower DRRR, the tightening effects of DRRR is also much bigger on the S\&M sized banks than that on large banks. The PBC can consider applying much lower DRRR to the S\&M sized banks.

Our study also has some limitations. For the first model, in fact, the best data used in the model is actually monthly or seasonal data, but due to the data limitation, we can only get the annual data. For panel data analysis, four year data may be too short. For the second model, as we can just get the total loans made by the large banks and S\&M sized banks, we cannot get the monthly data for each bank and analyze in detail. These limitations will be solved when the data are available in the future.

\section{References}

[1] J. Peek and E. S. Rosengren, Bank Lending and the Transmission of Monetary Policy, in Conf. Ser. Reserv. Bank Bost. 47 (1995)

[2] G. Ma, X. Yan, and X. Liu, China's Evolving Reserve Requirements, in Discuss. Pap. Bank Finl. Inst. Econ. Transit. 1 (2011)

[3] C. Montoro and R. Moreno, BIS Q. Rev. March (2011)

[4] C. Borio and P. Disyatat, Unconventional Monetary Policies: An Appraisal (BIS Working Papers, 2009)

[5] S. E. Hein and J. D. Stewart, Econ. Rev. Reserv. Bank Atlanta 87, 41 (2002)

[6] F. Black, J. Financ. Econ. 2, 323 (1975)

[7] F. J. Fabozzi and T. B. Thurston, J. Financ. Quant. Anal. 21, 427 (1986)

[8] D. K. Osborne and T. S. Zaher, J. Bank. Financ. 16, 799 (1992)

[9] T. F. Cosimano and B. McDonald, J. Monet. Econ. 41, 57 (1998)

[10] J. D. Stewart and S. E. Hein, J. Financ. Res. 25, 367 (2002)

[11] A. K. Kashyap and J. C. Stein, in Natl. Bur. Econ. Res. Work. Pap. Ser. (1994)

[12] S. Van den Heuvel, Econ. Policy Rev. 8, 259 (2002)

[13] R. P. Kishan and T. P. Opiela, J. Money, Credit Bank. 121 (2000)

[14] S. Gray, Int. Montery Fund 11, (2011)

[15] J. A. Hausman, J. Econom. Soc.46,1251 (1978)

[16] C. K. M. Lau, China Econ. Rev. 21, 293 (2010)

[17] R. Davidson and J. G. MacKinnon, Estimation and Inference in Econometrics (Oxford University Press, 1993)

[18] S. Fan, R. Kanbur, and X. Zhang, Rev. Dev. Financ. 1, 47 (2011)

[19] J. G. MacKinnon, A. A. Haug, and L. Michelis, J. Appl. Econom. 14, 563 (1999)

[20] X. Zhang, Z. Ji, and Y. Cui, J. Econ. Res. (in Chinese) 7, 65 (2008)

[21] P. Pedroni and J. Y. Yao, J. Asian Econ. 17, 294 (2006) 